\title{
G scusem \\ COVID-19 in the Brazilian Oil Capital: the successful experience of public and private engagement
}

\section{Natália Martins Feitosa}

Universidade Federal do Rio de Janeiro, Instituto de Biodiversidade e Sustentabilidade NUPEM/UFRJ-

Macaé

\section{Bruno da Costa Rodrigues}

Universidade Federal do Rio de Janeiro, Instituto de Biodiversidade e Sustentabilidade NUPEM/UFRJMacaé

\section{Ana Cristina Petry}

Universidade Federal do Rio de Janeiro, Instituto de Biodiversidade e Sustentabilidade NUPEM/UFRJMacaé

\section{Keity Jaqueline Chagas Vilela Nocchi}

Universidade Federal do Rio de Janeiro, Instituto de Biodiversidade e Sustentabilidade NUPEM/UFRJMacaé

\section{Rodrigo de Moraes Brindeiro}

Universidade Federal do Rio de Janeiro, Departamento de Genética - Instituto de Biologia ICB/UFRJ

\section{Carla Zilberberg}

Universidade Federal do Rio de Janeiro, Instituto de Biodiversidade e Sustentabilidade NUPEM/UFRJ-

Macaé

\section{Cintia Monteiro-de-Barros}

Universidade Federal do Rio de Janeiro, Instituto de Biodiversidade e Sustentabilidade NUPEM/UFRJMacaé

\section{Flavia Borges Mury}

Universidade Federal do Rio de Janeiro, Instituto de Biodiversidade e Sustentabilidade NUPEM/UFRJMacaé

\section{Jackson de Souza Menezes}

Universidade Federal do Rio de Janeiro, Instituto de Biodiversidade e Sustentabilidade NUPEM/UFRJMacaé

\section{José Luciano Nepomuceno-Silva}

Universidade Federal do Rio de Janeiro, Instituto de Biodiversidade e Sustentabilidade NUPEM/UFRJ-

Macaé

\section{Manuela Leal da Silva}

Universidade Federal do Rio de Janeiro, Instituto de Biodiversidade e Sustentabilidade NUPEM/UFRJMacaé

\section{Marcio José de Medeiros}


Universidade Federal do Rio de Janeiro, Instituto de Biodiversidade e Sustentabilidade NUPEM/UFRJMacaé

\section{Raquel de Souza Gestinari}

Universidade Federal do Rio de Janeiro, Instituto de Biodiversidade e Sustentabilidade NUPEM/UFRJMacaé

\section{Alessandra da Silva de Alvarenga}

Universidade Federal do Rio de Janeiro, Instituto de Biodiversidade e Sustentabilidade NUPEM/UFRJMacaé

\section{Allan Pierre Bonetti Pozzobon}

Universidade Federal do Rio de Janeiro, Instituto de Biodiversidade e Sustentabilidade NUPEM/UFRJMacaé

\section{Carina Azevedo Oliveira Silva}

Universidade Federal do Rio de Janeiro, Instituto de Biodiversidade e Sustentabilidade NUPEM/UFRJMacaé

\section{Daniele das Graças dos Santos}

Universidade Federal do Rio de Janeiro, Instituto de Biodiversidade e Sustentabilidade NUPEM/UFRJMacaé

\section{Diego Henrique Silvestre}

Universidade Federal do Rio de Janeiro, Instituto de Biodiversidade e Sustentabilidade NUPEM/UFRJMacaé

\section{Graziele Fonseca de Sousa}

Universidade Federal do Rio de Janeiro, Instituto de Biodiversidade e Sustentabilidade NUPEM/UFRJMacaé

\section{Janimayri Forastieri de Almeida}

Universidade Federal do Rio de Janeiro, Instituto de Biodiversidade e Sustentabilidade NUPEM/UFRJMacaé

\section{Jhenifer Nascimento da Silva}

Universidade Federal do Rio de Janeiro, Instituto de Biodiversidade e Sustentabilidade NUPEM/UFRJMacaé

\section{Layza Mendes Brandão}

Universidade Federal do Rio de Janeiro, Instituto de Biodiversidade e Sustentabilidade NUPEM/UFRJMacaé

\section{Leandro de Oliveira Drummond}

Universidade Federal do Rio de Janeiro, Instituto de Biodiversidade e Sustentabilidade NUPEM/UFRJMacaé

\section{Lupis Ribeiro Gomes Neto}

Universidade Federal do Rio de Janeiro, Instituto de Biodiversidade e Sustentabilidade NUPEM/UFRJMacaé

\section{Raphael de Mello Carpes}


Universidade Federal do Rio de Janeiro, Instituto de Biodiversidade e Sustentabilidade NUPEM/UFRJMacaé

\section{Renata Coutinho dos Santos}

Universidade Federal do Rio de Janeiro, Instituto de Biodiversidade e Sustentabilidade NUPEM/UFRJMacaé

\section{Taynan Motta Portal}

Universidade Federal do Rio de Janeiro, Instituto de Biodiversidade e Sustentabilidade NUPEM/UFRJMacaé

\section{Amilcar Tanuri}

Universidade Federal do Rio de Janeiro, Departamento de Genética - Instituto de Biologia ICB/UFRJ

Rodrigo Nunes-da-Fonseca ( $\sim$ rodrigo.nunes.da.fonseca@gmail.com )

Universidade Federal do Rio de Janeiro, Instituto de Biodiversidade e Sustentabilidade NUPEM/UFRJMacaé

\section{Research Article}

Keywords: SARS-CoV-2, Symptom's analyses, RT-qPCR molecular test, epidemiological analysis

Posted Date: March 30th, 2021

DOI: https://doi.org/10.21203/rs.3.rs-319061/v1

License: (c) (i) This work is licensed under a Creative Commons Attribution 4.0 International License. Read Full License 


\section{Abstract \\ Background}

Brazilian strategy to overcome the spread of COVID-19 has been particularly criticized due to the lack of a national coordinating effort and an appropriate testing program. Here, a successful approach to control the spread of COVID-19 transmission is described by the engagement of public (university and governance) and private sectors (hospitals and oil companies) in Macaé, state of Rio de Janeiro, Brazil, a city known as the National Oil Capital.

\section{Methods}

Until the 38th epidemiological week, over two percent of the 206,728 citizens were subjected to symptom analysis and massive RT-qPCR testing by the Federal University of Rio de Janeiro, with positive individuals being notified up to 48 hours after swab collection. Geocodification and spatial cluster analysis were used to limit COVID-19 spreading in Macaé.

\section{Findings:}

Within the first semester after the outbreak of COVID-19 in Brazil, Macaé recorded $1.8 \%$ of fatality associated to COVID-19 up to the 38th epidemiological week, which was at least five times lower than the state capital (10.92\%). Overall, considering the successful experience of this joint effort of private and public engagement in Macaé, our data suggest that the development of a similar strategy country wise would have saved over 50,000 lives.

\section{Interpretation:}

Quarantine decree by the local government, molecular massive testing coupled to scientific analysis of COVID-19 spreading prevented the catastrophic consequences of the pandemic as seen in other populous cities within the state of Rio de Janeiro and elsewhere in Brazil.

\section{Introduction}

Coronaviridae is a family of RNA viruses well-known to infect a large variety of mammalian and avian hosts [1]. The genus betacoronavirus is particularly important for public health, since at least five strains have already been reported to infect humans, leading to mild diseases, such as the common cold, pneumonia as well as other severe respiratory illness. In the past two decades, previous severe respiratory disease infections by coronavirus, SARS-CoV and MERS-CoV, have provided evidence that these viruses could lead to pandemic outbreaks. The World Health Organization (WHO) reported a new strain of a coronavirus arising in China at the end of December 2019, with a strong pandemic potential [2]. In 
January 2020, SARS-CoV-2 was identified as the causative agent of Coronavirus Disease (COVID-19) and until August $30^{\text {th }}$ of the same year, over 25 million people had already been infected with over 800,000 deaths being recorded globally [3].

COVID-19 is characterized by dry cough and fever in about $60-70 \%$ of infected individuals, without major complications and medical intervention. However, $30-40 \%$ of those infected have evolved to severe respiratory disease, with $15-25 \%$ of individuals requiring long-term hospitalization with high mortality risk. Until September, 2020, Brazil had 4,455,386 confirmed cases of COVID-19 and 134,935 associated deaths, according to the Coronavirus Brazil Panel data (last updated on 9/17/2020 at 18:00h; SVS / MS 2020). All over the country, testing has been general limited to the ones with severe illnesses, and evidence suggests that COVID-19 related deaths in Brazil are greatly underestimated [4].

According to the Coronavirus Panel COVID-19 of Rio de Janeiro State Health Department (updated on 09/17/2020 at 18:40h; HEALTH STATE SECRETARY -RJ 2020), there were 246,843 confirmed cases in the state, with 17,453 deaths. While Brazil displayed an overall mortality rate of $3.02 \%$ until this date, the state of Rio de Janeiro had over twice this value (7.07\%). This high fatality rate in Rio de Janeiro was attributed to the low number of molecular tests being performed in the state compared with the National testing numbers.

Located in the interior of the state of Rio de Janeiro capital, the municipality of Macaé adopted a massive molecular (PCR) testing strategy followed by rapid isolation of positive individuals for COVID-19. This strategy was achieved by an alliance between municipality government and donations from private sectors which allowed a faster and cost-free molecular testing for the local population. Data analyses of 4,639 RT-qPCR tests, provide important insights of disease symptoms development, age and gender trends of positivity and deaths, as well as the neighborhood spatial distribution of COVID-19 in Macaé. Overall, Macaé displayed the lowest lethality rate in the state of Rio de Janeiro during the analyzed period (April-September 2020), indicating that the massive testing strategy was successful. These data suggest that a similar testing strategy between Brazilian public universities, research centers, government and private companies could have saved thousands of lives from COVID-19 deaths at other municipalities around the country.

\section{Methods}

\section{Nasopharyngeal swab collection, RNA extraction and RT-qPCR}

From April 12th to September 12th, 2020 ( $17^{\text {th }}-38^{\text {th }}$ epidemiological weeks), a total of 4,639 inhabitants displaying symptoms indicative of COVID-19 were medically examined the municipal Coronavirus Screening Center for COVID-19 (CSC) or at one of the four hospitals involved in the study. At each place, healthcare professionals recorded the patient's vital signs, applied an admission questionnaire, which covered essential epidemiological data, including the presence-absence of 16 clinical symptoms, as well as relevant personal information (residential address and work activity). Written informed consent was 
obtained from all participants and/or their legal guardians before starting the study. All methods were performed in accordance with the relevant guidelines and regulations. The study protocols were reviewed and approved by the Research Ethics Committee of the Federal University of Rio de Janeiro - Macaé (Protocol number 32868720.4.0000.5699). Study inclusion criteria included subjects with a diagnosis of COVID-19 and positive PCR-based testing for SARS-CoV-2 and ongoing symptoms and/or clinical findings consistent with acute COVID-19, who were separated by ages and gender. Study exclusion criteria included lack of willingness or ability to provide informed consent or lack of an appropriate legal guardian or representative to provide informed consent, or another medical contraindication to donate nasopharyngeal sample. Individual nasopharyngeal swabs were inserted into $15 \mathrm{~mL}$ conical tubes containing $2 \mathrm{~mL}$ Dulbecco's modified Eagle's culture medium (DMEM) and antibiotics (5,000 units per millimeter of penicillin and streptomycin). These conical tubes were delivered to the Institute NUPEMUFRJ, where they were stored up to 72 hours at $4^{\circ} \mathrm{C}$. $200 \mu \mathrm{L}$ of each sample were employed for extraction of nucleic acids, which was performed using magnetic beads (Magmax Magnetic Kit - Thermofisher) following manufacturer's instructions. For the final step, $50 \mu \mathrm{L}$ of elution buffer was used to elute the purified nucleic acids. Alternatively, this kit was substituted by a fast direct a simple commercial extraction solution easy Extract ${ }^{\mathrm{TM}}$, as recently described by similar methods $[5,6]$. 40uL of nasopharyngeal swab embedded in DMEM solution was added to 40uL of EasyExtract. The final solution was mixed with an automatic pipette and was followed by a two-step heating process of $65^{\circ} \mathrm{C}$ for six minutes and $98^{\circ} \mathrm{C}$ for two minutes. Real-time reverse transcription polymerase reactions (RT-qPCR) for the identification of SARS-CoV-2 positive samples were performed using a TaqMan ${ }^{\text {TM }}$ approach, as previously described in the Berlin [7] or the CDC [8] protocols. Reverse transcription and amplification reactions were performed using the Promega GoTaq ${ }^{\circledR}$ Probe 1-Step RT-qPCR System. Each $15 \mu \mathrm{L}$ reaction contained 5 $\mu \mathrm{L}$ of RNA template and $10 \mu \mathrm{L}$ of a solution containing reaction buffer, reverse transcriptase/Taq mixture and primer/probe mixture to a final concentration of $0.66 \mu \mathrm{M}$. All oligonucleotides were synthesized by Integrated DNA Technologies (lowa, USA) and ThermoScientific. The thermal cycling conditions used were $50{ }^{\circ} \mathrm{C}$ for $10 \mathrm{~min}$ for the reverse transcription, followed by $95^{\circ} \mathrm{C}$ for $2 \mathrm{~min}$ and then 45 cycles of 95 ${ }^{\circ} \mathrm{C}$ for $10 \mathrm{~s}$ and $58^{\circ} \mathrm{C}$ for $30 \mathrm{~s}$. RT-qPCR tests were considered positive when two regions of SARS-CoV-2 genomes were amplified. Patients were considered uninfected when amplification was successful only for the human internal control (RNAse P). All RT-qPCR assays were performed on a StepOnePlus ${ }^{T M}$ Real Time PCR System (Applied Biosystems).

\section{Symptom data analyses}

From April 12th to September 12th, 2020 (a total of 22 epidemiological weeks), detailed medical information of 3,495 individuals tested was recovered. The proportion of positive results were compared between gender among groups of individuals separated by age according to WHO, with the first age class being from 0 to 14 years old, then from 15 to 80 years old the age class interval was every 5 years, totalizing 15 age classes. Additionally, comparisons were also made among age classes that encompass professional activities (between 15 and 74 years old) and among the days after the first symptom onset, using the Test of Equal or Given Proportions, which assumes equal proportions in two or more groups. 
The test of Equal or Given Proportions was also performed to compare the rate of positive outcomes between two temporal windows of 11 epidemiological weeks. The three possible types of cointegration (Type 1: no trend; Type 2: linear trend; Type 3: quadratic trend) between absolute mortality and positive results series of two earlier epidemiological weeks with the Engle-Granger Test were tested. The two weeks lag was chosen after checking the observation that 14 days ( \pm 0.69 standard error) was the average time elapsed between RT-qPCR test and death of 75 fatal victims of COVID-19 in our cohort at Macaé.

Since the 16 symptoms included in the questionnaires presented a qualitative nature (1-0 or presenceabsence of a given symptom), we employed a multivariate analysis technique to explore the similarity of symptoms on CSC positive results between men and women from the 15 age classes. Multivariate analyses constitute the branch of mathematics that deals with the examination of numerous variables simultaneously and, therefore, they have been widely used in ecological studies with the aim of exploring the relationships of several characteristics measured on a number of individuals or communities, including microorganisms [9]; [10]. Herein, we dealt with a matrix of pairwise distances or dissimilarities between individuals based on their reported symptoms with the aim to ordinate them within a dissimilarity space limited to a low dimensional representation. Since multivariate analyses are generally sensitive to zero-inflated matrices, we excluded the three least reported symptoms (drowsiness, irritability and mental confusion), which were reported by less than $5 \%$ of the individuals. The Jaccard index was chosen to construct the distance-based matrix, since it is the most appropriate metric when variables are defined as $0-1$. The distance-based matrix was then submitted to a non-metric dimensional scaling (NMDS) with the function metaMDS in the 'vegan' package [11] in R 3.6.1, for visualization of the individuals on the two-dimensional space, according to their dissimilarity. Individuals presenting similar sets of symptoms are positioned close to one another, while those with dissimilar symptoms (e.g., not sharing any symptom) are positioned further apart. Compared to other ordination techniques, NMDS is recommended even when the relationship between dissimilarities and inter-object distances is nonlinear, as long as low stress values are obtained [12]. The stress value (from 0 to 1.0) measures how good the graphical representation is of the actual dissimilarities on the distance-based matrix. According to Quinn \& Keough [12], stress values greater than 0.3 indicate that the configuration is no better than arbitrary and therefore should not be interpreted.

Significant effects of gender and/or age class and their interaction on the distance-based matrix were assessed with a two-way permutational analysis of variance (PERMANOVA) performed with the function adonis in the 'permute' package [13] in R 3.6.1. By expecting that the NMDS would be able to reveal structure on the most and less shared symptoms among individuals, we descriptively compare the scores between men and women among age classes along the first and second NMDS axes (NMDS1 and NMDS2, respectively) and related them to the prevalence of the symptoms.

\section{Comparison of viral cycle thresholds (Cts)}


The $\Delta \mathrm{Ct}$ approach was chosen to compare the approximate viral load of nasopharyngeal swabs, where Cts values of RNAse $P(R P)$ endogenous control were subtracted from the arithmetic mean of $N 1$ and N2 targets of SARS-CoV-2 $(\Delta \mathrm{Ct}=(\mathrm{CtN} 1+\mathrm{CtN} 2) / 2-\mathrm{CtRP})$, for each positive patient $[14,15]$. The arithmetic mean of $\mathrm{Ct}$ values is usually employed when using multiple reference genes in relative analyses of gene expression studies [16], and was used here to the targeted genes under the assumption that the expression of $\mathrm{N} 1$ and $\mathrm{N} 2$ viral genes are not differentially regulated between infected individuals. When compared to the presentation of crude Ct values, the $\Delta \mathrm{Ct}$ approach has the advantage of providing a normalized $\mathrm{Ct}$ score, discounting for initial variations on swab collected biological material and also for the presence of possible polymerase inhibitors in the RT-qPCR reactions.

RT-qPCR positive patients were classified as mild or severe based on criteria previously defined by Liu et al. [14], which include any of these conditions: respiratory distress (respiratory frequency $\geq 30$ breaths/min), oxygen saturation at rest $\leq 93 \%$, severe disease complications leading to hospitalization and death in consequence of the infection. We also attempted to classify these patients in early and late infected cases based on the day of appearance of the first COVID-19 symptoms, as reported in the admission questionnaires. The boundary up to and after the 5th day from manifestation of the first symptoms was chosen to establish early and late classes (respectively $<5$ and $>5$ days), as the proportions of mild and severe cases were comparatively balanced between these two intervals.

The $\Delta \mathrm{Ct}$ of individuals were compared between mild and severe cases and between $<5$ and $>5$ days after the first symptom. Additionally, interactions among them were compared by analyses of variance (ANOVA), after checking for the residuals homoscedasticity with the function leveneTest, available in the package carData [17].

\section{Geocodification, spatial distribution and spatial cluster analysis}

The notification forms of the Brazilian Ministry of Health's Notification and Surveillance System were extracted from the Municipal Health Department of Macaé. The address data (street address, number, neighborhood and zip code) were used for the geocoding process. To describe the spatial distribution of COVID-19 occurrences in the municipality, each case location was plotted together with the case density

level curves, estimated using the Kernel smoothing method. The smoothed relative risk (SRR) was used to assess the spatial distribution of COVID-19 cases (deaths) [18]. This analysis allowed the comparison of deaths caused by COVID-19 among neighborhoods. To estimate the SRR, the geocoded cases (deaths) were grouped by neighborhood, and indirect standardization [35] was used to compute the expected number of cases for each neighborhood. The SRR then follows as the ratio of the observed number of events (cases and deaths) over the expected number:

$\mathrm{SRRi}=\mathrm{Oi} / \mathrm{Ei}$

where Oi represents the observed number of COVID-19 cases (deaths) in the area (neighborhood) i, and Ei represents the expected number of COVID-19 cases (deaths) for the area i. 
To assess the spatial dependence of the distribution of COVID-19 cases (deaths), the Moran's I coefficient of autocorrelation was calculated to obtain the SRR. Autocorrelation statistics for aggregated data provide an estimate of the degree of spatial similarity observed among neighboring values of an attribute over a study area [19].

The spatial analyses of the data and generation of the maps were performed using R 3.6.1. The Google Maps API was adopted from the R software package ggmap [20] to geocoding, the tmap package [21] was used to plot the maps, the smooth relative risks were estimated using the Dcluster package [22] and the package spdep [23] were used for the estimates and tests the Moran's I coefficient.

\section{Results}

\section{Macaé fatality rate was lower compared with other populous municipalities}

Macaé is located in the State of Rio de Janeiro, southeast of Brazil (Figure 1). Comparison of COVID-19 death rates showed that in six months of epidemic (up to the $38^{\text {th }}$ epidemiological week), Macaé had the lowest mortality rate among the 23 most populous municipalities (>125,000 inhabitants) in the state of Rio de Janeiro (Figure 1).

\section{Men actively working contracted COVID-19 at higher rates than women}

Essential activities of offshore companies and transport are still generally men-based worldwide, and these sectors did not stop during the quarantine in Macaé. On the other hand, public services, educational system and street commerce, which usually employs genders more equally were strongly restrained by municipal decrees. Only after five months, some of those sectors (i.e., non-essential commerce) were restarting traditional activities, whereas by October $18^{\text {th }} 2020$, presential activities in schools, universities and public departments had not yet restarted. During the study period, 297 women and 286 men between 15 and 74 years tested positive for COVID-19. Comparison of both genders showed a higher rate of men engaging in working activity compared to women (Chi2 $=24.681 ;$ d.f. $=1 ; p<0.001)$. A finer age scale interval showed an even clearer pattern, with men from the age of 35 onwards exerting a significantly higher working activity during quarantine than women (Age classes 15-34 years Chi2=1.150; d.f.=1; $p=0.284 ; 35-54$ years Chi2 $=25.40 ;$ d.f. $=1 ; p<0.001 ; 55-74$ years Chi2 $=8.036 ;$ d.f. $=1 ; p=0.005$ ) (Supl. Fig. 2 ). Taken together, these results suggest that men actively working were more exposed to infection and contracted COVID-19 at higher rates than women.

\section{Two distinct stages of COVID-19 spreading were identified in Macaé}

The increase in the number of tests over time at least partially reflects the carrying capacity of sampling processing at the NUPEM-UFRJ laboratory, which increased from an average of 38 to 430 tests per week, until reaching a stable rate of 400 tests, from the $31^{\text {th }}$ epidemiological week onwards (Fig. 3A). The ratio of positive RT-qPCR decreases throughout the epidemiological weeks, even though high fluctuations were recorded along the first 11 weeks (Fig. 3A). There were significant differences in the positive rates 
between two temporal windows, the first characterized by a low number of tests (Stage 1) and the other by a high number of tests (Stage 2$)(C h i 2=126.62 ;$ d.f. $=1 ; p<0.001)$ (Fig. 3BC). This fact may partially reflect the selection criteria of patients for RT-qPCR that arrived more severely ill at CSC during the first weeks of the pandemic and the effectiveness of the governance policies against the spread of the virus. A congruence between the number of positive tested and absolute deaths started to be observed only

after the $32^{\text {th }}$ epidemiological week (Fig. 5D) and this trend may explain the lack of cointegration between the number of positive results and the number of deaths for Types 1( $E G=-2.07 ; p=0.10), 2$ ( $E G=0.01$; $\mathrm{p}=0.10)$ and $3(\mathrm{EH}=0.95 ; \mathrm{p}=0.10)$. On Stage 2 , a constant ratio of $1: 10$ between fatality and positive outcomes was observed (Fig. 5E), even though both variables diminished with time.

\section{RT-qPCR tests were performed during ideal window for virus detection}

Irrespective of gender, most positive RT-qPCR results were from sample collections between the fourth and sixth day after the first symptoms (55\% of the women and $53 \%$ of the men) and there was no significant difference between gender on the overall representativeness among the days after the first symptoms (Chi2=18.077; d.f. $=19 ; p=0.517$ ) (Fig. 4). This finding reinforces that the ideal window for doing the RT-qPCR is between 3 and 8 days after symptom onset, regardless of the gender tested.

\section{Respiratory symptoms are associated with hospitalization}

Among the 3,751 tested for COVID-19 at the health center CSC and the hospital settings, 878 tested positive ( $51 \%$ from CSC and $49 \%$ from hospital). Symptoms related to respiratory disorders (i.e., cough and shortness of breath) were the most frequently reported by those requiring mostly intensive care in hospital settings, whereas varied and less frequent symptoms were more frequently reported by those with milder symptoms (Fig. 5). Among the latter, typical symptoms of flu, such as headache, myalgia, runny nose and sore throat were similarly reported by women and men, whereas loss of taste, anosmia and nausea and vomit were more typically reported by women (Fig. 5; Supl.. Fig. 3). But irrespective of gender, individuals younger than 40 years old reported more frequently headache, loss of taste, anosmia and sore throat, while individuals older than 40 reported more frequently myalgia and fever (Supl. Fig. 3). Independently of gender deaths were concentrated in individuals older than 50 years (Sup. Fig 4).

\section{Identity and frequency of symptoms vary depending on age and gender}

An analysis using the multidimensional space of the NMDS (see methods for details) showed a widely spread ordination of the positive tested men and women, reinforcing a general pattern of heterogeneity of their symptoms (Fig. 6A-B). The stress value (from 0 to 1.0) measures how good the graphical representation is of the actual dissimilarities on the distance-based matrix. According to Quinn \& Keough [12], stress values greater than 0.3 indicate that configuration is no better than arbitrary and therefore should not be interpreted. Since a stress value of 0.23 was observed in our dataset, the ordination was considered adequate. The centroids of the ordinated individuals significantly differ between gender and age classes (Fig. 6C). Since PERMANOVA analysis detected significant differences within both effects, age $(<40$ and $>40)$ and gender classes, it is possible to conclude that in general the identity and the 
frequency of the reported symptoms differ between men and women, but it is also dependent on age (Table 2; Supl. Fig. 3).

Detailed analysis showed that those significant differences among individuals are associated with the milder symptoms, such as loss of taste, anosmia and nausea-vomit, that prevailed among women (Supl. Fig. 3). In addition, there was also an effect of age on the identity and frequency of the reported symptoms. Interestingly, irrespective of gender, individuals younger than 40 years old reported more frequently headache, loss of taste, anosmia and sore throat, while individuals older than 40 reported more frequently myalgia and fever (Table 2; Supl. Fig. 3). These trends are reinforced by the comparison of the scores of positive tested individuals along the first two NMDS axes (Fig. 6C). Age has a stronger effect along NMDS1 (younger individuals with positive and older with negative scores, respectively) and gender along NMDS2, where men presented positive scores whereas women presented negative scores.

\section{Lack of correlation between $\Delta C t$ values from nasopharyngeal RT-qPCR swab tests and disease severity}

To understand if the differences of patients with mild and severe COVID-19 symptoms previously described (see Figure 5) can also be correlated with changes in the viral load from nasopharyngeal swabs, a RT-qPCR comparative analysis was performed using the $\Delta$ Ct values as a response variable (see [24] and references therein). Lower $\Delta \mathrm{Ct}$ values directly correspond to higher viral load in nasopharyngeal swabs. The results showed that the viral load clearly reduced with time after the appearance of the first symptoms, but this is perceptible only for mild COVID-19 patients (Figure 7). In contrast, patients presenting severe symptoms showed a lower viral load (higher $\Delta$ Ct values), independent of the day of the RT-qPCR test was performed $(<5$ or $>5$ ) (Table 3$)$.

\section{Highly populated neighborhoods contain COVID-19 RTq-PCR positive hotspots and deaths}

To understand if the RT-qPCR positive results and deaths were evenly distributed over Macaé city or were concentrated in specific neighborhoods, the smoothed relative risk (SRR) values (see methodology for details) were calculated. The analysis allowed to compare positivity and deaths rates among neighborhoods. SRR quintiles of positive RT-qPCR cases are displayed in Figure 8A with dark and light regions representing high and low SRR values, respectively. Similarly, Figure 8B shows the SRR quintiles of confirmed urban deaths. These maps indicate the distribution of positive RT-qPCR and death SRRs values along the city, and measures of spatial autocorrelation could be analyzed. In general, if the SRR values in the dataset are clustered spatially (high values cluster near other high values; low values cluster near other low values), the autocorrelation method of Moran's Index will be positive. When high values repel other high values, and tend to be near low values, the Index will be negative. The Moran Index statistic results were -0.035 ( $p$-value $=0.5264$ ) for SRR positive RT-PCR and -0.019 ( $p$-value $=0.3555)$ for SRR deaths, confirming that COVID-19 infections and deaths were evenly distributed along the city and not spatially concentrated. Maps of weekly geocoded RT-qPCR positivity and deaths were developed (Sup. Fig 5 and 6) and aggregated into single maps (Figure 8C and 8D). Our weekly comparative analysis

shows that at the $17^{\text {th }}$ epidemiological week positive RT-PCR cases were already spread along the city. 
Interestingly, there is a large correspondence between Figures $8 \mathrm{C}$ and $8 \mathrm{D}$ (positive RT-PCRs and death) showing that regions with high RT-PCR positivity region were also the ones corresponding to high death occurrences. Comparison of these data with population density (Sup. Fig 7) also highlights that positive RT-PCRs and deaths were concentrated in the neighborhoods in which the greatest number of inhabitants are found.

\section{Discussion}

Rio de Janeiro is one of the most populous Brazilian states and even though it has a diversified economy, the state relies mainly on the extraction of natural resources, such as oil and gas [25]. Located $200 \mathrm{~km}$ north of the state capital, Macaé has attracted dozens of oil and hundreds of outsourced companies in the last 50 years, which renders the municipality the title of the National Oil Capital [26]. Since the beginning of March 2020, when Macaé recorded the first COVID-19 cases, the municipal governance began publishing a series of decrees (available at [27]) that included the closure of schools and temples, restriction of all non-essential activities, rigorous control of the arrivals by installation of sanitary barriers on all major municipality entries and the creation of the municipal Coronavirus Screening Center for COVID-19 patients (CSC), in the city center. Additionally, an alliance between the municipal governance, the Institute of Biodiversity and Sustainability of the Federal University of Rio de Janeiro in Macaé (NUPEM-UFRJ) and several oil industry related companies and hospitals allowed the implementation of a new laboratory that was urgently adapted for such a sanitary emergency, with the aim to set up the gold standard technique for SARS-Cov2 identification, the RT-qPCR. Consequently, from the $17^{\text {th }}$ epidemiological week onwards (April $12^{\text {th }}, 2020$ ), samples from nasopharyngeal swabs from CSC and four associated hospitals were collected and delivered to a recently created laboratory at NUPEM-UFRJ for RT-qPCR analyses.

In the present study it was observed a higher percentage of positive COVID-19 men at working ages (between 25-54) than women in Macaé (Figure 2). Research has shown that women are highly underrepresented in most extractive industries. The U.S. Department of Labor defines a male-dominated sector as one where women constitute less than a quarter of the total workforce [28]. Macaé is one of those oilproducing cities, thus, presenting a highly men biased workforce. Therefore, this result can be directly correlated with the presence of male-dominated workforce in the city.

Another interesting observation from our data regards the distribution of symptoms among the positive cases (Figure 5). COVID-19 symptoms have been described over six months by now [29] and our data support previous observations that symptoms related to respiratory disorders (i.e cough and shortness of breath) were most frequently reported by those requiring most intensive care in the hospital settings (Figure 5). As previously observed [30], absolute deaths increased within age classes independently of gender in Macaé, Rio de Janeiro, Brazil, between April $12^{\text {th }}$ and September $12^{\text {th }} 2020$. This increase in deaths with ages has been reported by several studies $[30,31]$ highlighting that age is one of the most important death risk factors. Altogether, our data provides a framework for clinical doctors to access the most frequent symptoms which might lead to hospitalization. 
The correlation between $\Delta$ Ct values and COVID-19 severity can also be discussed from our data. Briefly, there was no correlation between viral load, evaluated by $\Delta \mathrm{Ct}$ values, and disease severity (Figure 7). Although in principle counterintuitive, our data suggests that patients with mild symptoms may display higher viral load at the time of the exam than the severely affected patients. Interestingly, [32] have reported a similar finding when comparing viral loads between hospitalized and non-hospitalized New York patients. These authors argued that higher viral loads observed in patients presenting mild symptoms may reflect the elapsed time from infection onset, as viral loads usually peak during the presymptomatic stage or shortly after the manifestation of first symptoms of COVID-19 and then show a slow decline during the following two-weeks [33]. Then, while many patients recover from the disease in this two-week period, a small proportion of them will suffer from progressive health deterioration, even with lower viral load using nasopharyngeal swabs. Thus, most patients identified as severe cases may have been infected and replicating SARS-CoV-2 several days before presenting the first symptoms. Together with the report from [32] our observations corroborate previous studies showing that long lasting COVID-19 syndrome is not necessarily correlated with higher viral loads, but rather with lower ones [33]. The larger sample number presented here and the more robust statistical tests than most of the previous studies reinforces this conclusion. This is of special concern for health authorities, as asymptomatic or mildly symptomatic individuals may offer more risk of spreading SARS-CoV-2 than severely compromised patients.

Another noteworthy finding from the current study comprised the COVID-19 positivity distribution along Macaé city (Figure 8, Sup. Fig 5-7). Highly populated areas from the city containing banks, supermarkets and pharmacies concentrate both RT-qPCR positive and death cases, suggesting that these essential trade activities might foster disease spreading along the city. Importantly, population density and SSR RTqPCR positivity were directly correlated with spatial death occurrence along the city over the whole analyzed period ( $17^{\text {th }}$ and $38^{\text {th }}$ epidemiologic week), thus, authorities should focus on containing the spread of the disease mainly at these specific locations. Previous analysis at two states of Brazil, Ceará and São Paulo, also provided evidence that metropolitan highly populated areas showed the greatest number of COVID-19 cases [34,35]. Spread of the virus can be highly associated with the mobility of people by means of transportation, such as planes and buses [35]. Importantly, one of the hotspots of Macaé COVID-19 RT-qPCR data overlaps with the largest bus station in the city, providing further evidence that people's mobility and population concentration are essential factors for disease spreading.

COVID-19 stable transmission in Brazil has been estimated to be established during early-mid March 2020 ( $11^{\text {th }}$ to $12^{\text {th }}$ epidemiological weeks) and differences in viral introductions were observed depending on the state, e.g., while in Ceará, Northeast Brazil, genome sequences were grouped in a single clade, the Amazon state presented several international and national introductions along the pandemic [36]. Macaé might represent an important hotspot for introduction of new SARS-Cov-2 lineages in Brazil from other countries, since oil and gas workers arrive daily in the city. Thus, COVID-19 control in Macaé and other surrounding cities might be an additional challenge if new viral lineages are introduced from abroad as new lineages are constantly being identified [36]. 
To sum up, a well-designed strategy of testing and isolation of positive individuals was successful to mitigate the effects of COVID-19 in an important oil production city of Brazil until September, 2020. Symptom analysis showed that respiratory effects are associated with a worse disease prognosis. Geocoded spatial analysis indicated that highly populated areas display the largest number of RT-qPCR positive cases and deaths. Altogether, based on death comparison with cities lacking extensive molecular tests suggest that more than 50,000 lives could have been spared if similar strategies of massive testing would have been applied country wise.

\section{Declarations}

Acknowledgments: The Institute of Biolodiversity and Sustainability NUPEM from Federal University of Rio de Janeiro would like to thank the Ministério Público Federal, Ministério Público do Trabalho, UNIMED, Irmandade São João Batista, Prefeitura Municipal de Macaé, TRF-4, Justiça Federal of Macaé, Justiça Federal of Itaperuna, AdUFRJ and FAPERJ(E-26/210.176/2020). The complete list of donors is available at http://transparencia.coppetec.ufrj.br/pesquisa-covid19-macae.php.

Competing interests: The author(s) declare no competing interests.

\section{References}

1. Schoeman D, Fielding BC. Coronavirus envelope protein: current knowledge. Virol J. 2019;16(1):69. doi: 10.1186/s12985-019-1182-0. PubMed PMID: 31133031; PubMed Central PMCID: PMCPMC6537279.

2. WHO. Coronavirus disease (COVID-19) 2020 [19. November 2020]. Available from: https://www.who.int/emergencies/diseases/novel-coronavirus-2019/question-and-answers-hub/q-adetail/coronavirus-disease-covid-19.

3. Report W-W. Coronavirus disease (COVID-19) Weekly Epidemiological Update. 2020.

4. Hallal PC, Hartwig FP, Horta BL, Silveira MF, Struchiner CJ, Vidaletti LP, et al. SARS-CoV-2 antibody prevalence in Brazil: results from two successive nationwide serological household surveys. Lancet Glob Health. 2020;8(11):e1390-e8. doi: 10.1016/S2214-109X(20)30387-9. PubMed PMID: 32979314; PubMed Central PMCID: PMCPMC7511212.

5. Ladha A, Joung J, Abudayyeh O, Gootenberg J, Zhang F. A 5-min RNA preparation method for COVID19 detection with RT-qPCR. . 2020;v.20200405.

6. Wozniak A, Cerda A, Ibarra-Henriquez C, Sebastian V, Armijo G, Lamig L, et al. A simple RNA preparation method for SARS-CoV-2 detection by RT-qPCR. Sci Rep. 2020;10(1):16608. doi: 10.1038/s41598-020-73616-w. PubMed PMID: 33024174; PubMed Central PMCID: PMCPMC7538882.

7. Corman V, Bleicker T, Brünink S, Drosten C. Diagnostic detection of 2019-nCoV by real-time RT-PCR 2020 [16-11-2020]. 
8. Prevention CfDCa. CDC 2019-Novel Coronavirus (2019-nCoV) Real-Time RT-PCR Diagnostic Panel https://www.fda.gov/media/134922/download2020.

9. Gauch HJ. Multivariate analysis in community ecology. : Cambridge University Press, Cambridge, UK. 298p.Gauch HG Jr. 1982. ; 1982.

10. Yang J, Jiang H, Dong H, Y. L. A comprehensive census of lake microbial diversity on a global scale. Science China Life Sciences. 2019; 62(10):1320-31. doi: .https://doi.org/10/1007/s11427-018-95259.

11. Oksanen J, Blanchet G, Friendly M, Kindt R, Legendre P, McGlinn D, et al. vegan: Community Ecology Package. R package version 2.5-6. 2019.

12. GP Q, MJ K. Experimental design and data analysis for biologists. : 11th Ed. Cambridge University Press, Cambridge, UK. 537p.; 2013.

13. GL S. Functions for Generating Restricted Permutations of Data. . 2019. p. R package version 0.9-5.

14. Liu Y, Yan LM, Wan L, Xiang TX, Le A, Liu JM, et al. Viral dynamics in mild and severe cases of COVID-19. Lancet Infect Dis 2020a. ;6:656-7. . doi: doi: 10.1016/S1473-3099(20)30232-2. .

15. Liu Y, Liao W, Wan L, Xiang T, Zhang W. Correlation Between Relative Nasopharyngeal Virus RNA Load and Lymphocyte Count Disease Severity in Patients with COVID-19. Viral Immunol. 2020. doi: 10.1089/vim.2020.0062. PubMed PMID: 32297828.

16. Riedel G, Rudrich U, Fekete-Drimusz N, Manns MP, Vondran FW, Bock M. An extended DeltaCT-method facilitating normalisation with multiple reference genes suited for quantitative RT-PCR analyses of human hepatocyte-like cells. PLoS One. 2014;9(3):e93031. doi: 10.1371/journal.pone.0093031. PubMed PMID: 24658132; PubMed Central PMCID: PMCPMC3962476.

17. J. F. carData: Companion to Applied Regression Data Sets. R package version 3.0-3. 2019. .

18. Clayton D, Kaldor J. Empirical Bayes estimates of age-standardized relative risks for use in disease mapping. Biometrics. 1987;Sep;43(3):671-81.

19. Pfeiffer DK, Paul T, Timothy R, Robinson P, Stevenson M, Clements A. Local estimates of spatial clustering. Spatial Analysis in Epidemiology2008

20. Kahle D, Wickham H. ggmap: Spatial Visualization with ggplot2. . The R Journal [Internet]. 2019; 5(1): [144-61 pp.].

21. Tennekes M. tmap: Thematic Maps in R. Journal of Statistical Software. 2018;84(6):1-39. doi: 10.18637/jss.v084.i06.

22. Gómez-Rubio V, Ferrándiz-Ferragud J, López-Quílez A. Detecting clusters of disease with R. . Journal of Geographical Systems. 2005; 7, (2):189-206.

23. Bivand RS, Pebesma E, Gomez-Rubio V. Applied spatial data analysis with R: Springer, NY. http://www.asdar-book.org/. 2013.

24. Rao SN, Manissero D, Steele VR, J. P. A Systematic Review of the Clinical Utility of Cycle Threshold Values in the Context of COVID-19. Infect Dis Ther. 2020;9(3):573-86. doi: 10.1007/s40121-02000324-3. 
25. Geiger PP. Rio de Janeiro, Brazil 2020. Available from: https://www.britannica.com/place/Rio-deJaneiro-Brazil/Cultural-life.

26. Office MM. Macaé Economic Data http://www.macae.rj.gov.br/city/conteudo/titulo/socio-economicdata2011.

27. Office MMs. Decrees to control COVID-19 spreading http://www.macae.rj.gov.br/saude/conteudo/titulo/coronavirus-informacoes-e-orientacoesimportantes) 2020.

28. The Advocates for Human Rights Minneapolis MU. Promoting Gender Diversity and Inclusion in the Oil, Gas and Mining Extractive Industries. 2019.

29. National Center for Immunization and Respiratory Diseases (NCIRD) DoVD. Symptoms of Coronavirus 2020. Available from: https://www.cdc.gov/coronavirus/2019-ncov/symptomstesting/symptoms.html.

30. Roser M, Ritchie H, Ortiz-Ospina E, Hasell J. Coronavirus Pandemic (COVID-19). Published online at OurWorldlnData.org. Retrieved from: 'https://ourworldindata.org/coronavirus' [Online Resource]2020. Available from: https://ourworldindata.org/mortality-risk-covid\#case-fatality-rate-of-covid-19-by-age.

31. Mallapaty S. The coronavirus is most deadly if you are older and male - new data reveal the risks. Nature. 2020;585:16-7. doi: https://doi.org/10.1038/d41586-020-02483-2.

32. Argyropoulos KV, Serrano A, Hu J, Black M, Feng X, Shen G, et al. Association of Initial Viral Load in Severe Acute Respiratory Syndrome Coronavirus 2 (SARS-CoV-2) Patients with Outcome and Symptoms. Am J Pathol. 2020;190(9):1881-7. doi: 10.1016/j.ajpath.2020.07.001. PubMed PMID: 32628931; PubMed Central PMCID: PMCPMC7332909.

33. He X, Lau EHY, Wu P, Deng X, Wang J, Hao X, et al. Temporal dynamics in viral shedding and transmissibility of COVID-19. Nat Med. 2020;26(5):672-5. doi: 10.1038/s41591-020-0869-5. PubMed PMID: 32296168.

34. Pedrosa NL, Albuquerque NLS. Spatial Analysis of COVID-19 cases and intensive care beds in the State of Ceara, Brazil. Cien Saude Colet. 2020;25(suppl 1):2461-8. doi: 10.1590/141381232020256.1.10952020. PubMed PMID: 32520290.

35. Rex FE, Borges CAS, Kafer PS. Spatial analysis of the COVID-19 distribution pattern in Sao Paulo State, Brazil. Cien Saude Colet. 2020;25(9):3377-84. doi: 10.1590/1413-81232020259.17082020. PubMed PMID: 32876254.

36. Candido DS, Claro IM, de Jesus JG, Souza WM, Moreira FRR, Dellicour S, et al. Evolution and epidemic spread of SARS-CoV-2 in Brazil. Science. 2020;369(6508):1255-60. doi: 10.1126/science.abd2161. PubMed PMID: 32703910; PubMed Central PMCID: PMCPMC7402630.

\section{Tables}

Due to technical limitations, tables are only available as downloads in the supplementary files section. 


\section{Figures}

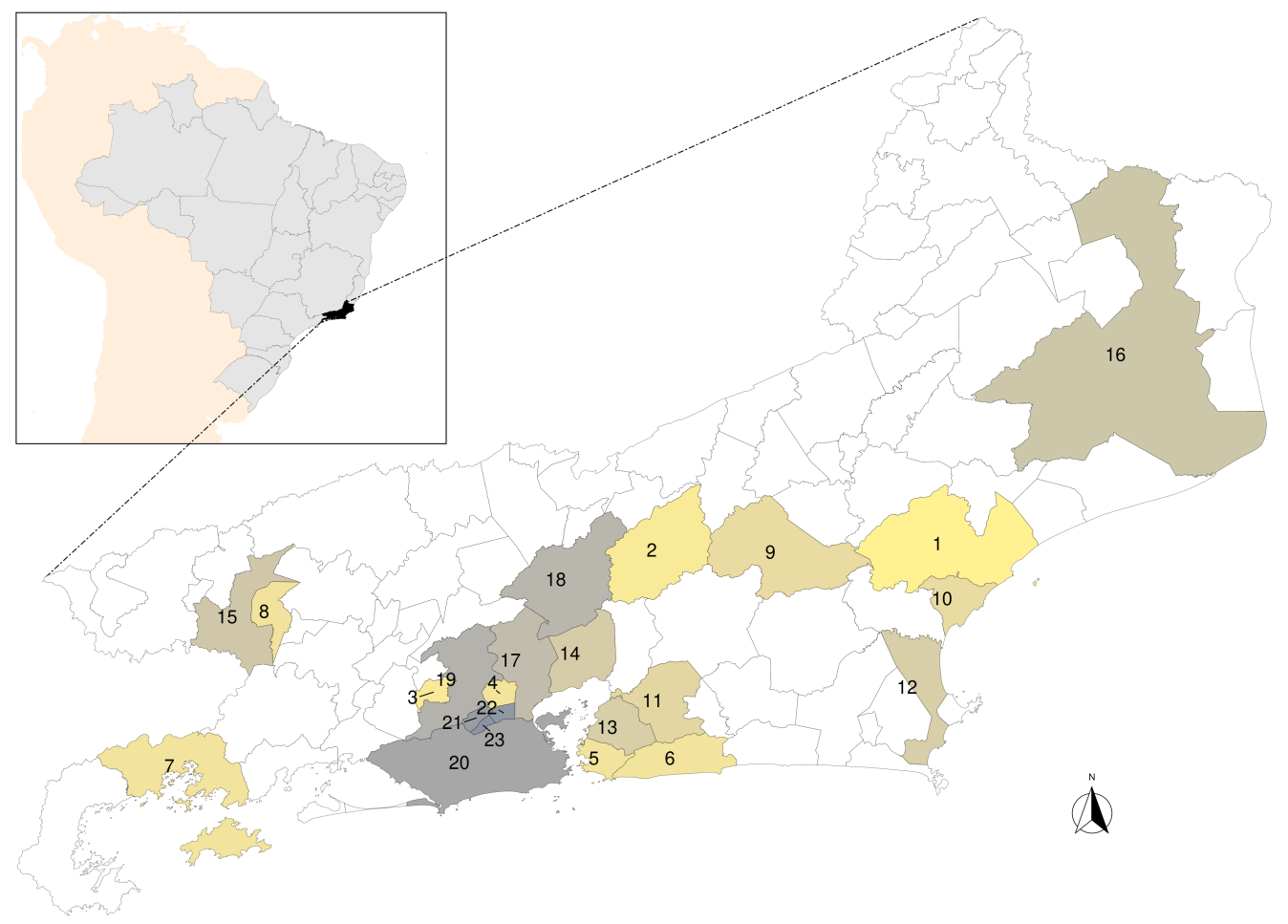

Legend:

(Case-Fatality Rate (\%) - Municipality Name)

1 1.8-Macaé

2 2.6 - Teresópolis

3 2.7- Queimados

4 3.2 - Belford Roxo

5 3.3 - Niterói

\begin{tabular}{lll}
6 & 3.3 - Maricá \\
\hline & 3 & $3.3-A n g a d$
\end{tabular}

$\begin{array}{lll}7 & 3.3 \text { - Angra dos Reis }\end{array}$

$\begin{array}{ll}8 & 3.4 \text { - Volta Redonda }\end{array}$

9 4.2 - Nova Friburgo

$10 \quad 4.2$ - Rio das Ostras

114.7 - Itaboraí

$12 \quad 5.7$ - Cabo Frio

135.8 - São Gonçalo

14 5.9-Magé

156.5 - Barra Mansa

16 6.6 - Campos dos Goytacazes

177.8 - Duque de Caxias

188.6 - Petrópolis

199.2 - Nova Iguaçu

2010.7 - Rio de Janeiro

21 12.2 - Mesquita

2212.8 - São João de Meriti

2313.5 - Nilópolis

\section{Figure 1}

Macaé, the National Oil Capital, occupying the lowest fatality rate due to COVID-19 among the 23 most populous municipalities (>125,000 inhabitants) of the state of Rio de Janeiro, Brazil. Source: Rio de Janeiro Health State Department up to the 38th epidemiological week. Note: The designations employed and the presentation of the material on this map do not imply the expression of any opinion whatsoever on the part of Research Square concerning the legal status of any country, territory, city or area or of its authorities, or concerning the delimitation of its frontiers or boundaries. This map has been provided by the authors. 


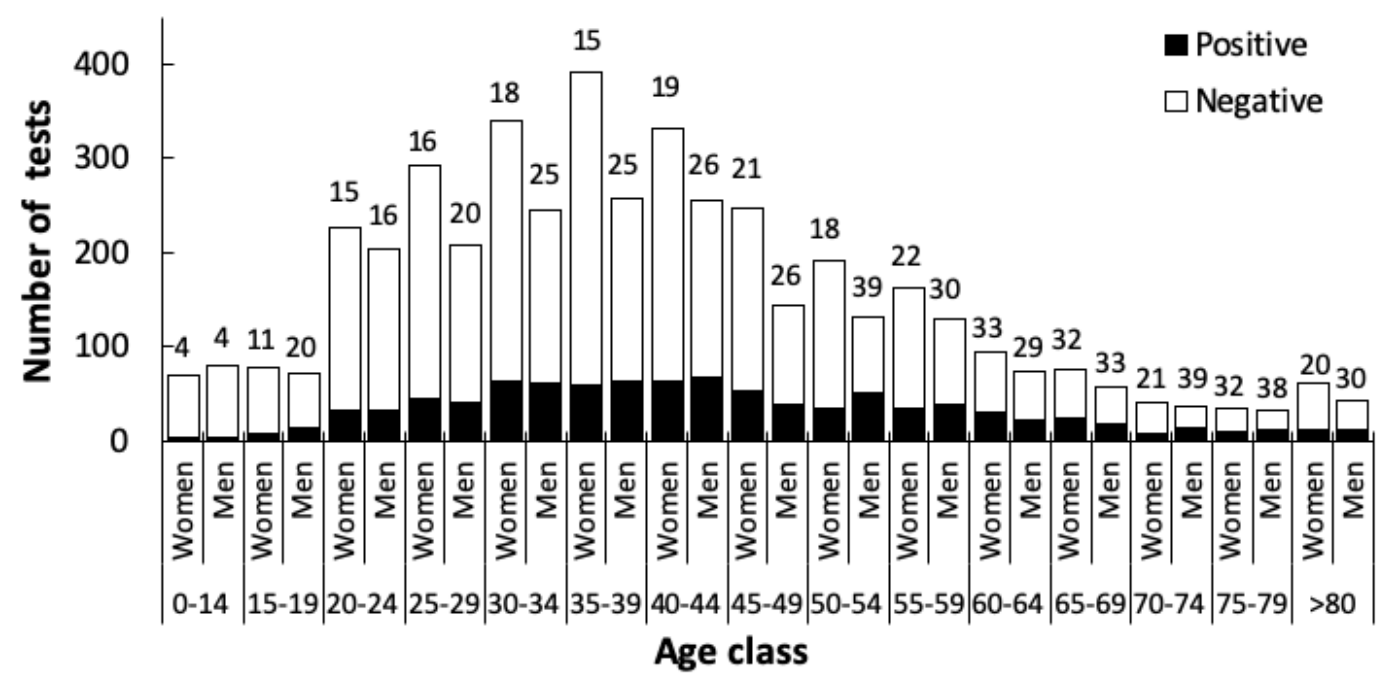

Figure 2

Number and percentage of positive individuals among the 4,639 tests for COVID-19 RT-qPCR in Macaé, State of Rio de Janeiro, Brazil, according gender (Men = 1,986; Women = 2,653), between April 12th and September 12th, 2020. Numbers above columns refer to the percentage of positive results within each gender and age class. See Table 1 to identify age classes with significant differences between gender (in bold). 


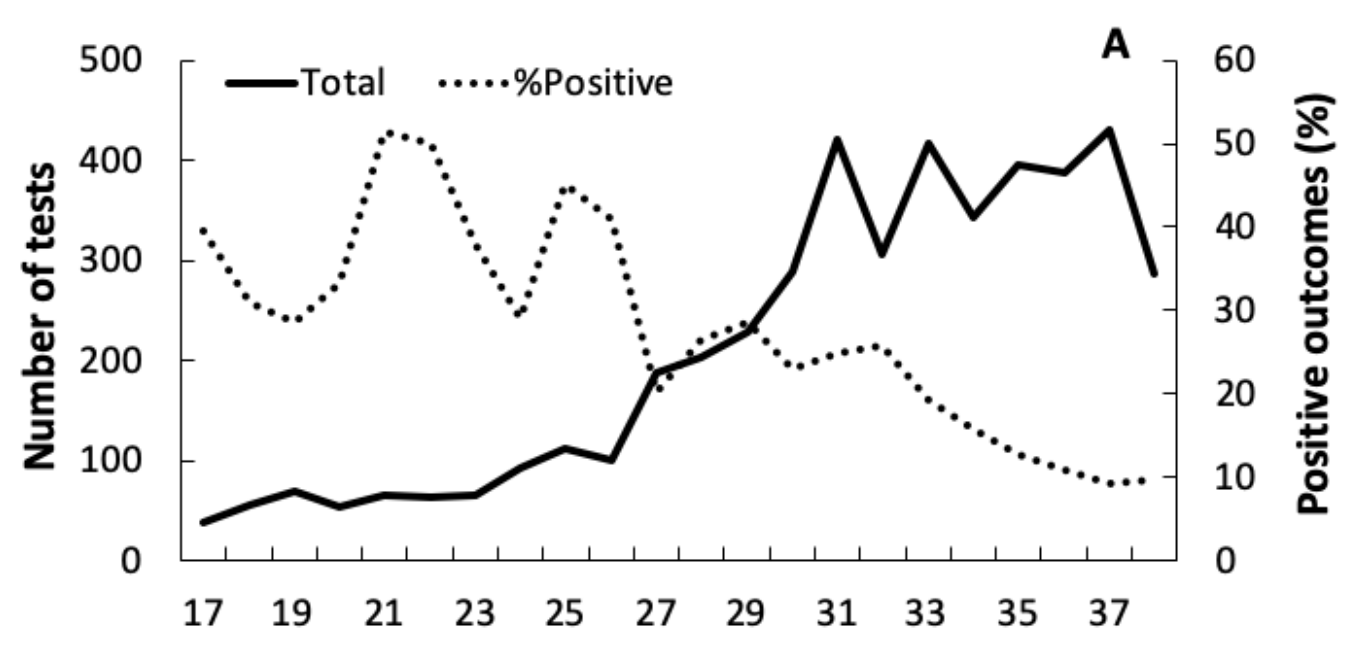

\section{Epidemiological week}
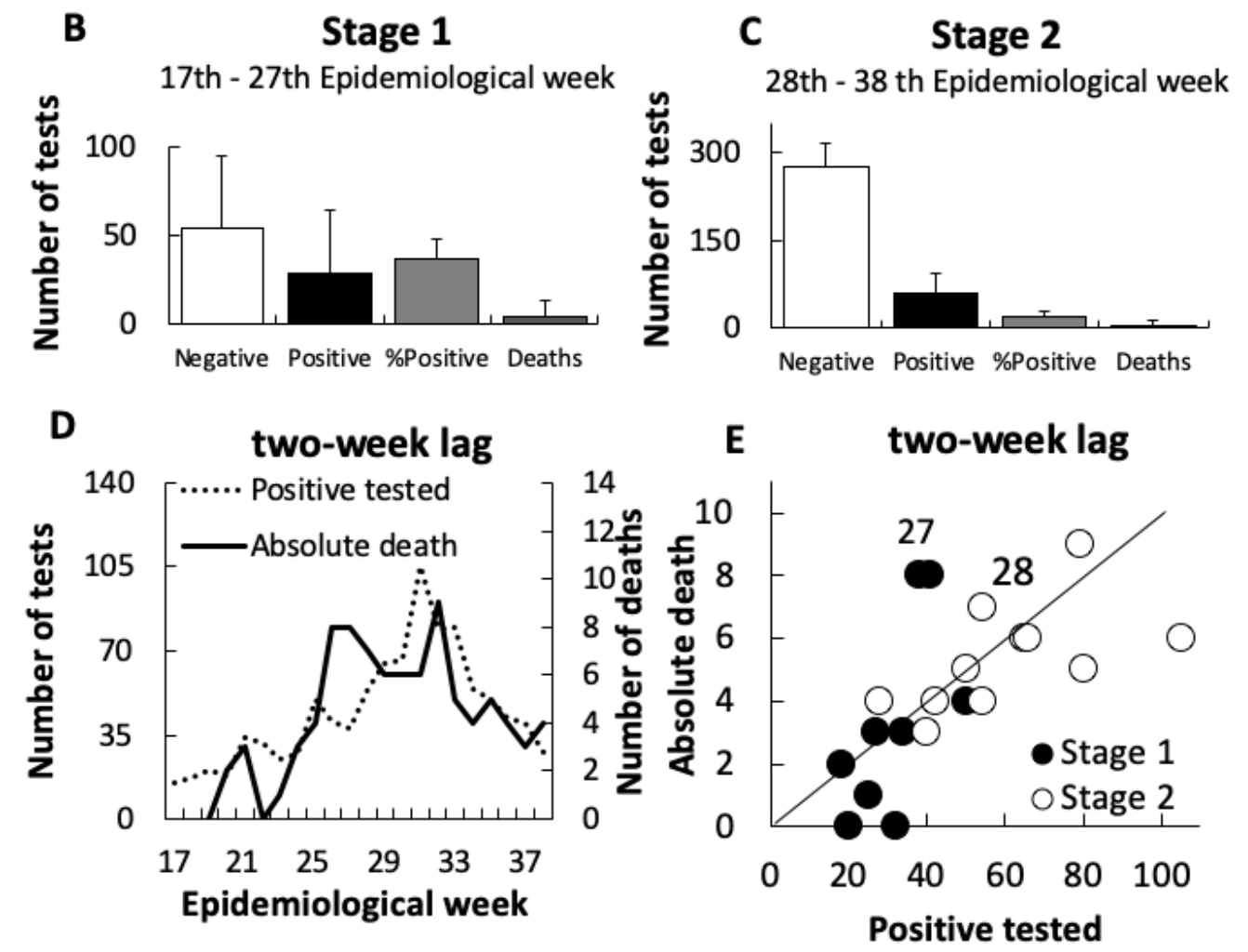

Figure 3

Relationship between the 4,611 COVID-19 RT-qPCR tests and positive result rates in Macaé, State of Rio de Janeiro, Brazil, between April 12th and September 12th, 2020. Note scale differences in B and C. The diagonal in E represents a 1:10 ratio in absolute death and positive outcomes. 


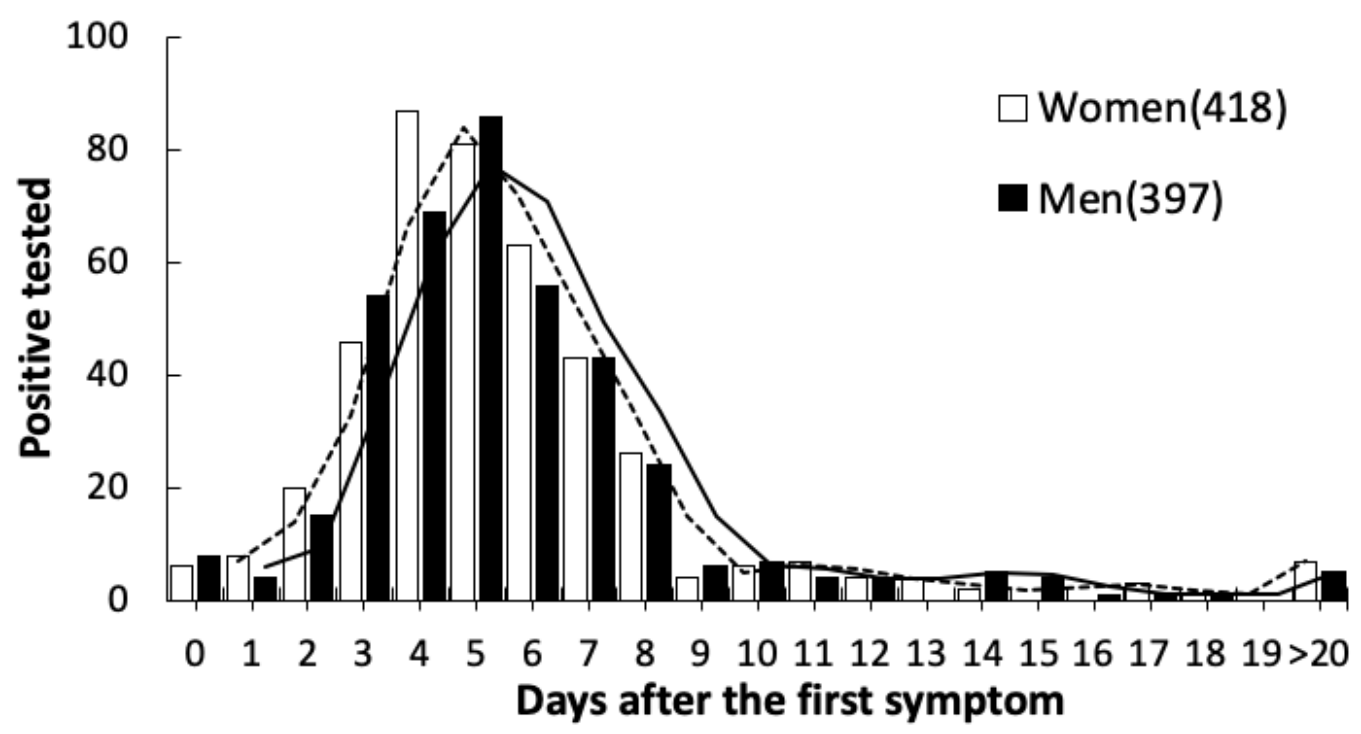

Figure 4

Distribution of the 815 positive tests for RT-qPCR COVID-19 by gender and days since the first symptom. This analysis is limited to patients from the municipal Coronavirus Screening Center for COVID-19 (CSC), Macaé, state of Rio de Janeiro, Brazil, between April 12th and September 12th, 2020. 155 cases were excluded from the analysis, since the day of the first symptom was not available. 


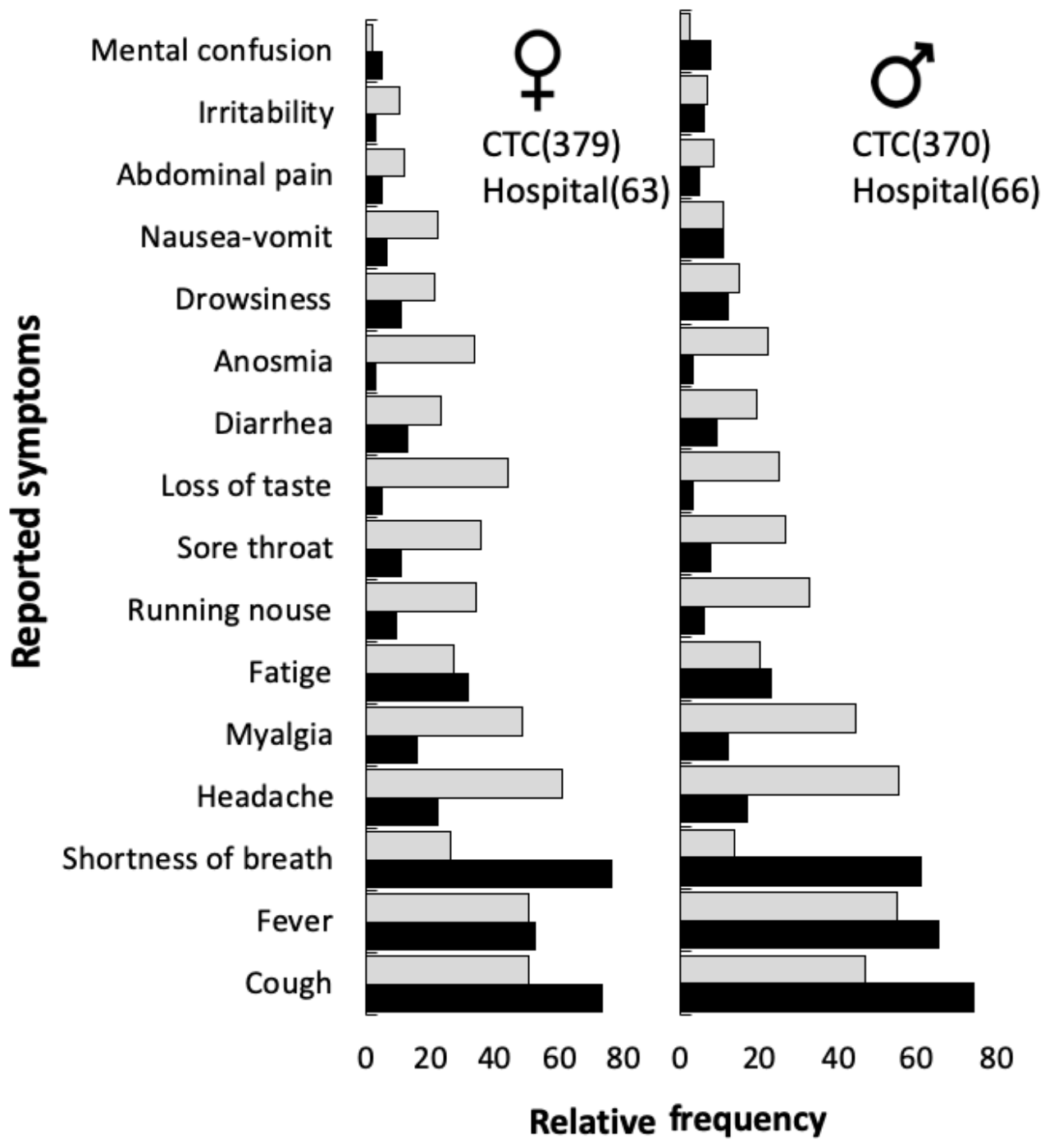

Figure 5

Prevalence of symptoms reported by 878 patients that tested positive for COVID-19 in CSC and the hospital settings of Macaé, state of Rio de Janeiro, Brazil, between April 12th and 12th September 2020. Number of positive tests are in brackets. 

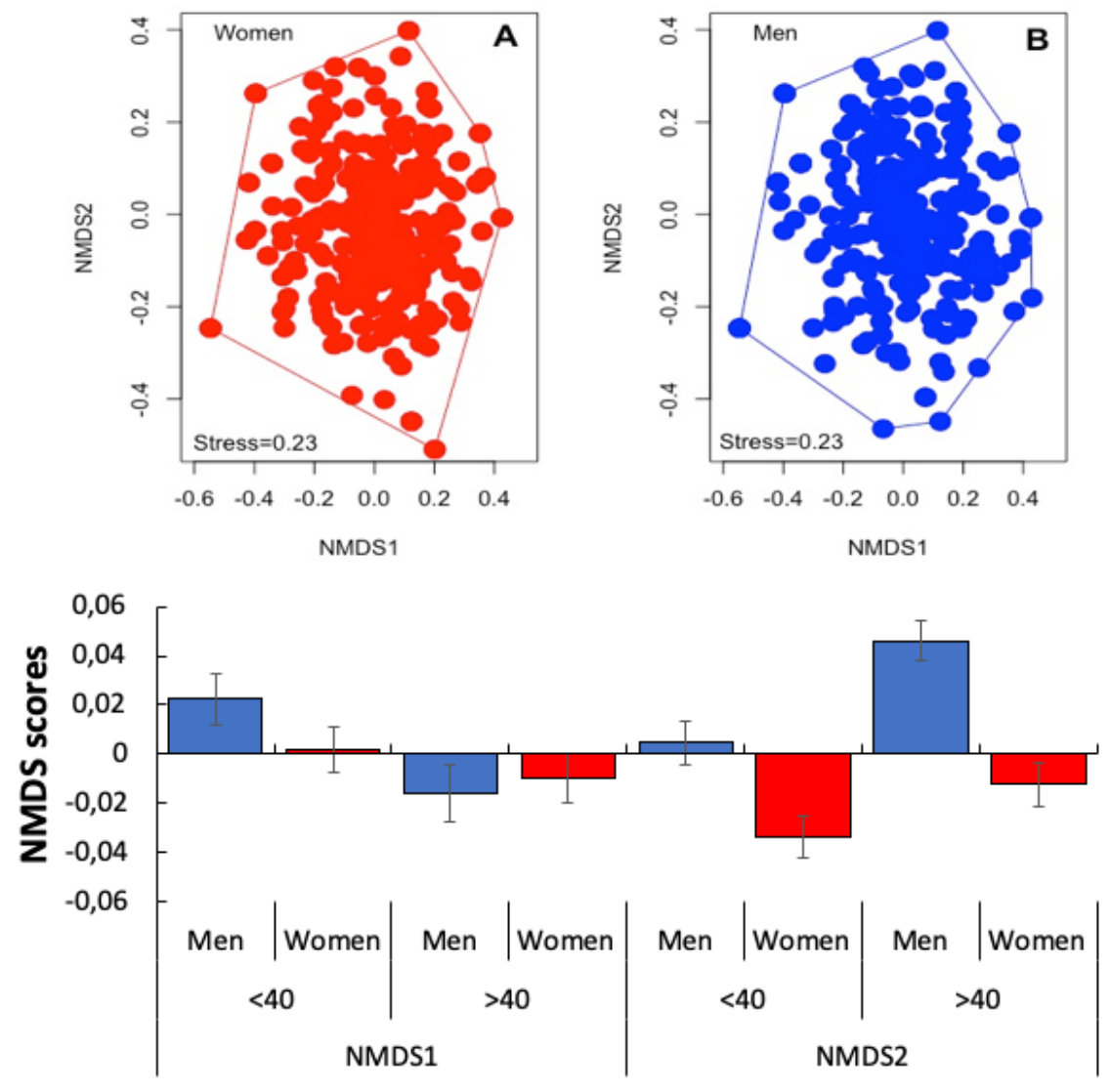

\section{Figure 6}

Ordination of women (A) and men (B) positively tested for COVID-19 in the municipal Coronavirus Screening Center for COVID-19 (CSC) on a multidimensional space formed by the two axes of the NMDS. Mean scores ( \pm standard error) between gender and age class in $\mathrm{C}$. 


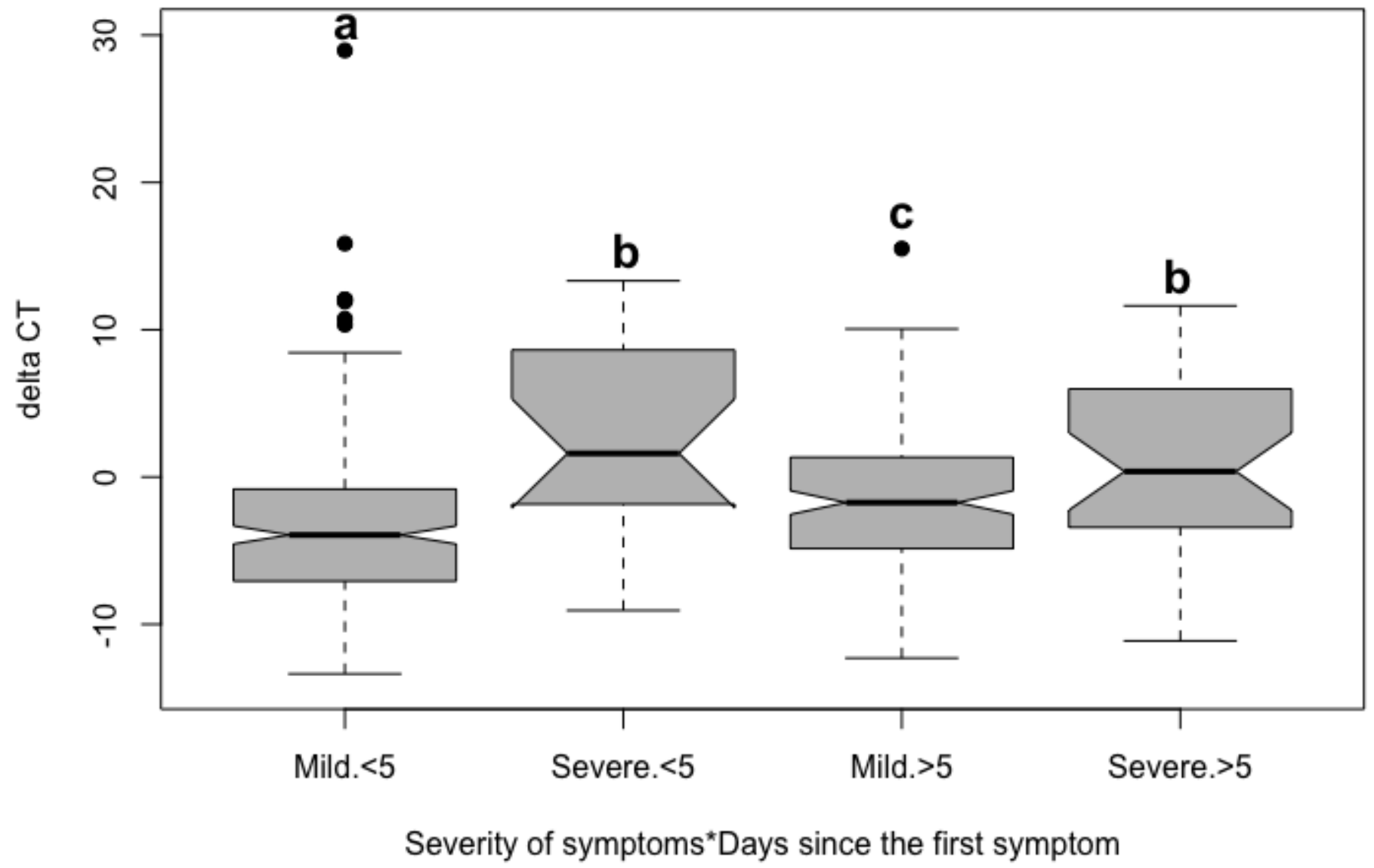

Figure 7

$\triangle \mathrm{Ct}$ of SARS-CoV-2 positive patients with mild and severe symptoms of COVID-19. Patient RT-qPCR results were separated in four different groups based on days after the first symptoms and severity of the disease. Mild $<5$ are $\Delta$ Ct values from 257 patients with mild COVID-19 symptoms tested until 5 days from the first symptoms [89\% of them from the municipal Coronavirus Screening Center for COVID-19 patients (CTC], Severe $<5$ are 20 patients hospitalized ( $80 \%$ of them) early after infection, or non-hospitalized patients with severity-related symptoms or still COVID-19 associated fatalities. The same classification was adopted for the 158 Mild $>5$ ( $85 \%$ of them from CTC) and 32 Severe $>5$ ( $78 \%$ of them from hospitals) patients with more than five days of symptoms. Significant differences among groups are represented by different letters above boxplots. 


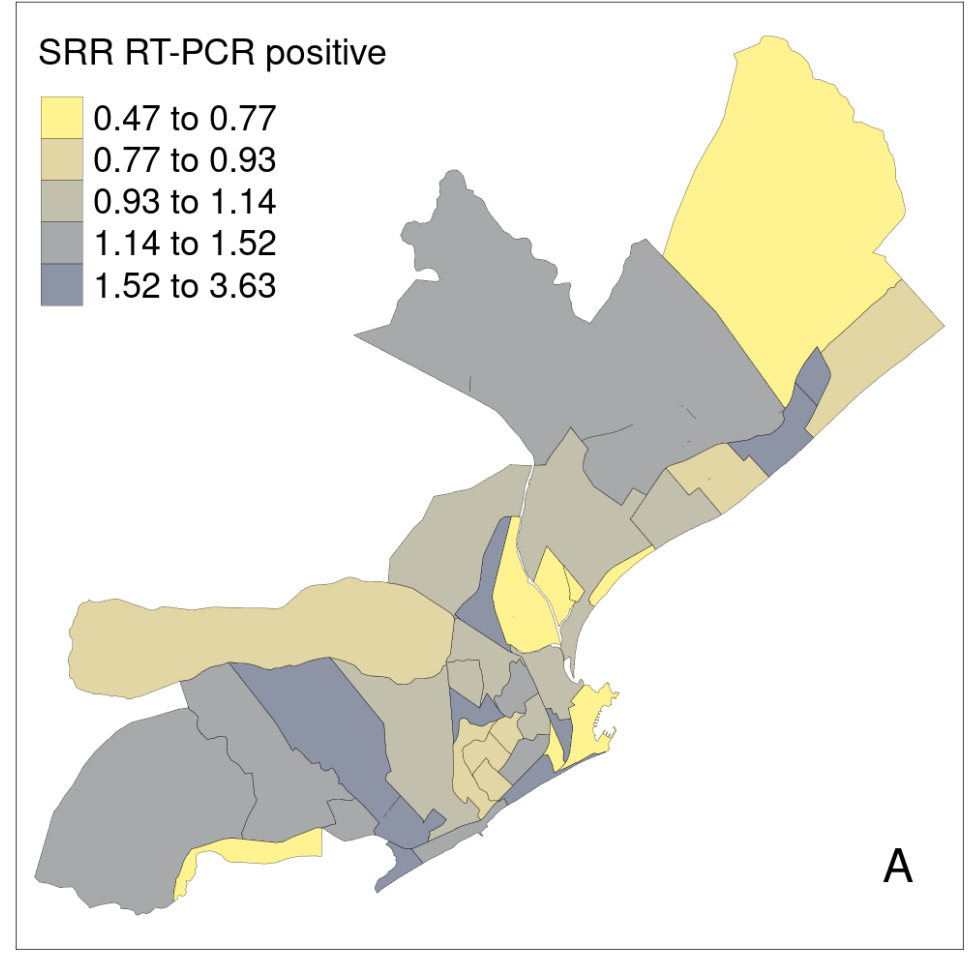

\section{SRR death}

0.77 to 0.93

0.93 to 1.14

1.14 to 1.52

1.52 to 3.63

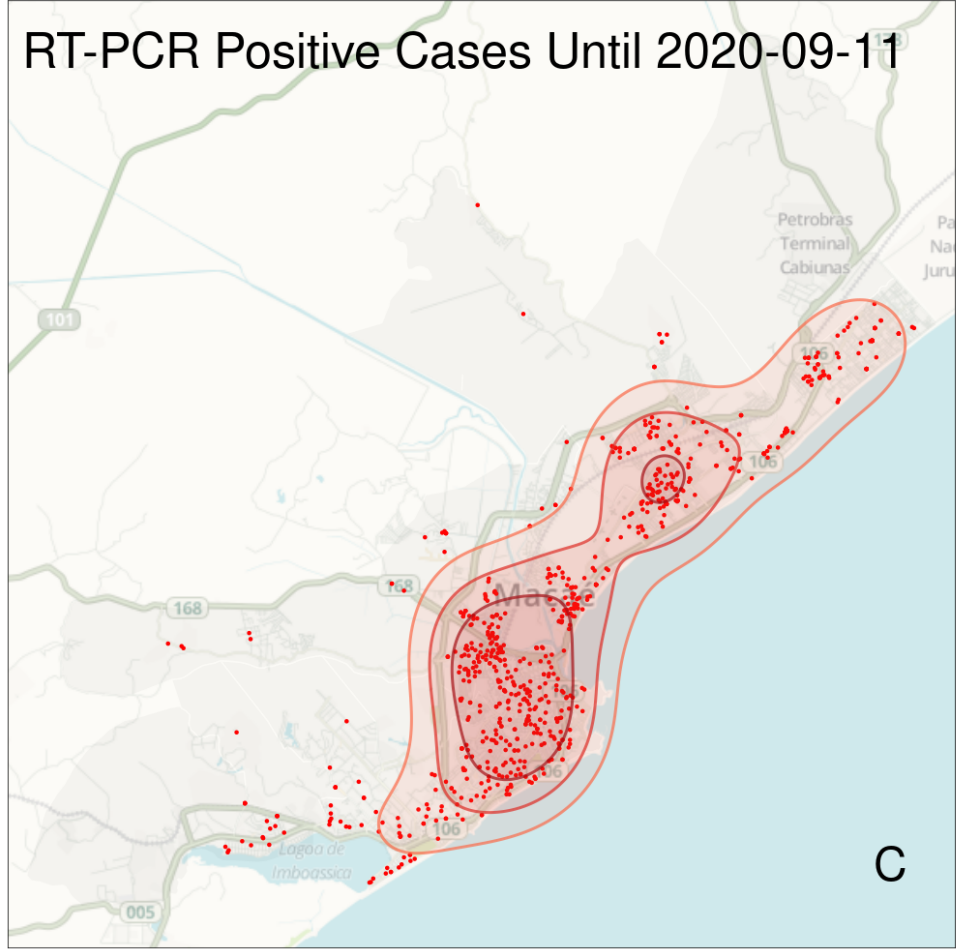

\section{Confirmed Deaths Until 2020-09-11}

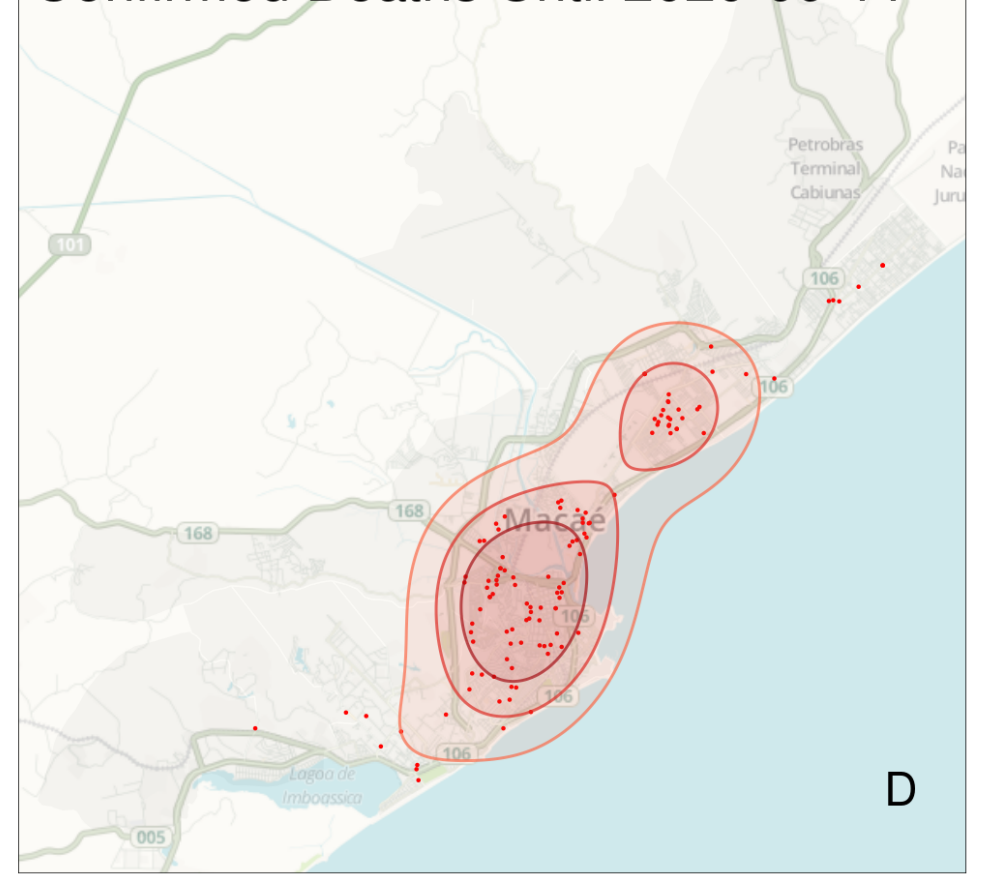

\section{Figure 8}

Spatial distribution of accumulated RT-qPCR positive cases and deaths in Macaé, Rio de Janeiro. (A-B) Map representation of the different neighborhoods of Macáe, RJ and SSR representation of RT-qPCR positivity (A) and deaths (C). (C-D) The exact locations of each occurrence (case and death) and the density level curves with 25,50 and $75 \%$ of the estimated cases using the Kernel smoothing method.

\section{Supplementary Files}


This is a list of supplementary files associated with this preprint. Click to download.

- Table1.tif

- Table2.tif

- Table3.tif

- SupFileMuldisciplinaryanalysis01022021.docx.pdf

- SupFileMuldisciplinaryanalysis01022021.docx.pdf 